\title{
CREATIVE PERFORMANCE: DAMPAK WORK ENVIRONMENT DAN CREATIVE SELF-EFFICACY (Studi Kasus di PT. Putra Mojo Maju Jaya Abadi)
}

\author{
Sesilya Kempa \\ Fakultas Bisnis dan Ekonomi, Universitas Kristen Petra \\ email: sesilya.kempa@petra.ac.id \\ Stephen Eric \\ Fakultas Bisnis dan Ekonomi, Universitas Kristen Petra \\ email: stepheneric3@gmail.com
}

\begin{abstract}
ABSTRAK
Penelitian ini bertujuan untuk menganalisis dampak work environment (WE) terhadap creative performance $(\mathrm{CP})$ melalui mediasi creative self-efficacy (CSE) karyawan PT. Putra Mojo Maju Jaya Abadi. Jenis penelitian ini termasuk dalam jenis penelitian kuantitatif. Sampel yang digunakan adalah sebanyak 67 responden dengan teknik purposive sampling. Proses perhitungan dan analisis penelitian menggunakan progam aplikasi software Partial Least Square (PLS). Metode pengumpulan data penelitian dilakukan dengan penyebaran kuisioner dengan menggunakan skala likert lima poin sebagai alat ukur. Hasil penelitian menunjukkan bahwa kualitas lingkungan kerja akan mempengaruhi tingginya efikasi diri kreatif yang selanjutnya akan mempengaruhi kreativitas seseorang dalam bekerja. Namun kualitas lingkungan kerja tidak mempengaruhi langsung creative performance seseorang.
\end{abstract}

Kata Kunci: Work Enrivonment, Creative Self-Efficacy, Creative Performance. 


\section{PENDAHULUAN}

Teknologi merupakan sebuah sarana yang dapat membantu aktivitas dan kelangsungan bagi kehidupan manusia. Perkembangan teknologi zaman sekarang sudah mencapai titik yang disebut "Industry 4.0 and Society 5.0". Perkembangan tersebut juga menuntut sebagian aspek bidang pekerjaan untuk bisa semakin kreatif dan inovatif demi bertahan dalam persaingan ekonomi zaman sekarang. Mayoritas bisnis yang telah dibangun pada zaman sekarang sudah bisa langsung beradaptasi dengan teknologi yang sudah ada seperti Tokopedia, Bukalapak, dan lain-lain. Namun, industri manufaktur yang telah dibangun pada tahun 1900-an juga dituntut oleh perkembangan zaman untuk menjadi sesuai dengan Industri 4.0 agar bisa tetap bersaing dan produktivitas yang juga cenderung stabil. Faktor terpenting yang dibutuhkan agar bisa menyeimbangkan antara manufaktur serta kondisi perkembangan teknologi adalah creativity performance. Creativity performance merupakan output dari pekerjaan yang ditambahkan dengan nilainilai kreatifitas selama proses pembentukan dari input pekerjaan.

Creativity performance di Indonesia masih tergolong cukup rendah karena berdasarkan data Global Creativity Index tahun 2015 Indonesia ada pada peringkat 115 dari 139. Peringkat tersebut dinilai berdasarkan tingkat teknologi, talent, dan toleransi pada negara tersebut (Katadata, 2016). Cakupan tersebut apabila disempitkan menjadi provinsi Jawa Timur saja maka dapat diamati bahwa provinsi Jawa Timur terutama industri kayu dalam tahun 2013 hingga 2015 mengalami peningkatan dari 330 industri menjadi 353 industri (Badan Pusat Statistik, 2018). Data dari BPS menunjukkan bahwa pada tahun 2013 hingga 2015 tenaga perusahaan yang bergerak dalam industri kayu mengalami penurunan tenaga kerja dari 353 perusahaan mengalami penurunan dari 166 ke 153 hingga pada akhirnya 143 tenaga kerja. Faktor tingkat teknologi, talent, dan toleransi berdampak besar terhadap creativity performance melalui aspek work environment serta creative self-efficacy pada diri individu. Hanya ada segelintir perusahaan yang bisa dikatakan "cukup kreatif" di Indonesia dan itu pun hanya perusahaan yang hanya memberikan platform teknologi kepada masyarakat (Badan Pusat Statistik, 2018).

Menelusuri ke dalam industri perkayuan terutama dalam kayu ringan seperti kayu sengon, jarang sekali tingkat produksi kayu sengon mencapai tahap finished good dan lebih sering di produksi dan dijual secara barecore atau setengah jadi. Bentuk setengah 
jadi ini menyebabkan banyak industri kayu hanya berkecimpung sebagai 'media pemotong' saja dan susah sekali ekspansi ke bidang yang lain. Bentuk work environment seperti ini juga memberikan sugesti dan motivasi kepada karyawan yang bekerja di industri tersebut hanya sebagai 'tukang potong' saja. Data survey dari Qerja menunjukkan bahwa work environment menjadi faktor terbesar yaitu sebesar 35\% dan hasil dari survey itu juga mengatakan bahwa work environment ini sangat berdampak besar bagi performa seorang individu meskipun perlu ditunjang dengan fasilitas yang memadai serta upah dan tunjangan yang sesuai juga (Qerja, 2018). Beberapa bukti menunjukkan bahwa work environment yang fisikal secara substansial berkontribusi pada pengetahuan kreativitas karyawan yang juga mendukung praktik SDM untuk memperkuat kapasitas inovasi organisasi dengan mempengaruhi pengambilan keputusan para arsitek dan desainer interior tentang desain tempat kerja fisik yang mendukung misalkan seperti kantor dan bangunan perusahaan (Dul, Ceylan, \& Jaspers, 2011).

Kecocokan antara work environment yang sesuai dengan diri seorang karyawan dapat menghasilkan self-efficacy pada dirinya sendiri dalam mengerjakan sebuah tugas. Self-efficacy merupakan rasa percaya diri seseorang dalam menyelesaikan sebuah tugas yang diberikan kepada dirinya (Bandura, 1995). Rasa percaya diri yang tumbuh dalam karyawan akan semakin cepat dalam menyelesaikan banyak tugas yang ditanggungkan kepada dirinya, namun berbeda hal jika karyawan tersebut bisa menyelesaikannya dengan cara 'out of the box'. Penyelesaian tugas dengan cara yang 'out of the box' menunjukkan creative self-efficacy pada diri seseorang. Creative self-efficacy adalah kepercayaan diri terhadap kreativitas diri dalam menyelesaikan sebuah masalah atau tugas sehingga jika diri individu merasa cukup kreatif, maka sebagian hal yang dilakukannya akan diselesaikan dengan cara-cara yang kreatif (Tierney \& Farmer, 2002). Individu-indivudu yang memiliki creative self-efficacy biasanya bekerja dalam sebuah bidang yang mengharuskan dirinya untuk berpikir secara luas akan potensi produk yang dihasilkan oleh perusahaannya sendiri yang sering kali berujung kepada inovasi produk yang sebelumnya harus dilakukan perencanaan produk.

Dalam lingkup perusahaan mebel, sesuai yang dinyatakan oleh Waketum Bidang Organisasi DPP Himpunan Industri Mebel dan Kerajinan Indonesia (HIMKI) Abdul Sobur bahwa HIMKI ingin mendorong pelaku industri ini untuk terus meningkatkan inovasi dan kreativitas sehingga dapat menghasilkan produk-produk unggulan yang 
memiliki nilai tambah optimal dan dapat menjadi market leader di pasar global. Di sisi lain, akan terbangun citra positif di tingkat internasional bahwa Indonesia adalah negara penghasil produk mebel dan kerajinan terbaik di dunia. Produk mebel dan kerajinan Indonesia, kata Sobur, sangat diminati dunia internasional salah satunya adalah yang berbahan baku rotan dan sengon. Produk rotan dan sengon di Indonesia merupakan produk ramah lingkungan, memiliki keunikan tersendiri yang dihasilkan oleh tangantangan terampil dan juga memiliki daya tahan yang lebih kuat daripada jenis kayu yang lain. Abdul Sobur juga menyatakan bahwa produk mebel dan kerajinan berbahan baku rotan pernah menjadi produk mewah dan ikon di kawasan Eropa, Amerika dan kawasan Asia-Afrika lainnya di mana masyarakat kelas menengah atas di sana cenderung mengisi rumahnya dengan mebel dan kerajinan berbahan natural (Vision Media, 2016).

Hal ini juga bertujuan untuk meningkatkan creative performance dari karyawan terhadap kerajinan kayu dan mebel. Dalam usaha meningkatkan kreativitas karyawan dan pengusaha maka diadakan acara pelatihan peningkatan kapasitas UKM mebel di Jawa Timur. Disampaikan juga bahwa diharapkan acara ini dapat memberikan manfaat dan menambah pengetahuan para pengrajin dalam turut berpartisipasi dalam perdagangan kayu legal. Dipahami bahwa tuntutan pasar internasional terhadap produk-produk ramah lingkungan terus meningkat oleh karena itu untuk dapat masuk dalam pasar internasional maka para pengrajin mebel dan kerajinan kayu di Jawa Timur harus mampu memenuhi tuntutan pasar internasional, khususnya terkait dengan penggunaan bahan baku kayu, yang jelas asal usul dan legalitasnya (ASMINDO, 2020).

Penambahan ilmu pengetahuan diharapkan dapat meningkatkan upaya karyawan dan pengusaha untuk meningkatkan inovasi dan kreativitas dalam usaha mebel dan kerajinan kayu. Upaya-upaya tersebut dapat dipastikan meningkatkan self-efficacy individu karena dapat berdampak langsung dikarenakan pengalaman yang didapatkan. Banyak dukungan dari pemerintah untuk meningkatkan kreativitas baik untuk karyawan sendiri ataupun hasil produksinya untuk pasar internasional dengan cara mengadakan acara besar seperti Salone Del Mobile di Milan salah satunya. Acara tersebut juga mendorong agar seluruh anggota perusahaan yang ikut serta agar menunjukkan kreativitasnya yang terbaik dalam skala internasional. Karyawan juga dipastikan 'diperas' agar bisa menghasilkan kreativitas yang tinggi. Aktivitas ini akan menambah pengalaman yang juga dapat berujung kepada creative self-efficacy karyawan yang dapat 
dimplementasikan kedepannya dan bisa menjadi evaluasi dan refleksi untuk peningkatan kualitas creative performance.

Menurut data yang dipaparkan oleh beberapa peneliti sebelumnya, work environment dapat dibedakan menjadi dua dimensi yaitu work environment sosial organisasionaldan work environment fisikal (Dul \& Ceylan, 2010). Work environment juga memiliki fungsi sebagai kumpulan kolektif dari knowledge sharing, motivasi, procedural justice, dan promosi yang mendorong karyawan untuk menghasilkan lebih banyak ide kreatif (Tsai, Horng, Liu, \& Hu, 2015). Instrumen yang terdapat dalam work environment akan berdampak besar terhadap tingkat self-efficacy atau creative selfefficacy dan juga berdampak kepada creative performance karena mediasi yang bagus dari work environment (lingkungan kreatif, supportive, well-facilitated) akan menumbuhkan persepsi terhadap diri seseorang untuk bisa beraktivitas dan berkreasi dengan caranya sendiri namun tetap bisa memecahkan masalah atau yang bisa disebut sebagai creative performance. Hal ini berbanding lurus sehingga apabila mediasi work environment yang buruk, maka proses pembentukan tingkat creative self-efficacy akan menurun dan hasil yang dikerjakan berupa creative performance akan tidak sesuai ekspektasi. Creative performance terkadang tidak berupa hasil akhir atau finished good, melainkan bisa berupa work-in-progress yang sudah terbentuk rapi dan sistematis seperti perencanaan inovasi produk.

Perencanaan inovasi produk yang didasari oleh faktor work environment yang sesuai yang disertai dengan creative self-efficacy juga akan menghasilkan sebuah kinerja kreativitas dari karyawan itu sendiri atau yang biasa disebut creative performance. Creative performance sendiri berdampak besar terhadap output sebuah perusahaan karena dapat menyangkut langsung terhadap faktor untuk berinovasi serta berkreasi terhadap varian produk yang ada pada perusahaan tersebut. PT. Putra Mojo Maju Jaya Abadi selaku perusahaan yang bergerak dalam bidang industri kayu sengon perlu diteliti untuk menguji apakah nilai-nilai untuk melaksanakan creative performance sudah tercapai dan apakah bisa creative performance itu sendiri mendorong tingkat kapasitas produksi dan profit dari PT. Putra Mojo Maju Jaya Abadi tersebut.

Produk yang menjadi fokus utama hingga saat ini bagi PT. Putra Mojo Maju Jaya adalah produksi hasil olahan kayu sengon seperti papan triplek, kayu balok, dan serbuk kayu sengon. Beberapa dari hasil olahannya di ekspor ke Taiwan menggunakan pihak 
ketiga yang merupakan logistik langganannya dan sebagian dari olahan tersebut sementara ini dijadikan mebel terutama meja, kursi, dan lemari yang berbahan dasar dari serbuk kayu yang melalui tahapan press dan dirangkai menggunakan paku. Produk yang menggunakan bahan serbuk kayu merupakan hak merk milik PT. Putra Mojo Maju Jaya Abadi sendiri dan untuk produksi mebel dengan bahan kayu balok diperuntukkan bagi pihak perusahaan lain yang bekerja sama dengan PT. Putra Mojo Maju Jaya Abadi. Sebagian besar merupakan produk kustom sehingga bisa menerima jenis barang yang berbeda seperti keranjang bayi, meja bar, dan ornamen hiasan rumah. Permintaanpermintaan khusus dari pihak perusahaan lain mengharuskan PT. Putra Mojo Maju Jaya Abadi untuk menyusun jajaran karyawan yang cukup sederhana karena ingin lebih fokus terhadap hasil penjualan. Dalam operasionalnya, kreativitas dari karyawan di divisi desain dan produksi sangat dibutuhkan dalam menghasilkan produk unik.

Penelitian yang dilakukan ini juga ditujukan untuk menutupi kesenjangan penelitian dimana ada yang memaparkan bahwa hubungan antara work environment dan creative self-efficacy cenderung bertolak belakang yang disebabkan oleh pengucilan di work environment (De Clercq, Haq, \& Azeem, 2019). Penelitian ini dilakukan dengan menginvestigasi tingkat efikasi sebagian karyawan di PT. Putra Mojo Maju Jaya Abadi dan menelusuri apakah rancangan bentuk work environment sudah sesuai dengan yang diharapkan para karyawan. Kedua faktor ini jika sudah diperbaiki atau ditingkatkan lagi maka dampaknya akan berpengaruh terhadap creative performance secara signifikan. Hal ini akan coba dibuktikan melalui penelitian yang akan dilaksanakan di PT. Putra Mojo Maju Jaya Abadi.

\section{Rumusan Masalah}

Rumusan masalah dalam penelitian ini adalah apakah kualitas work environment dan tingkat creative self-efficacy pada karyawan PT. Putra Mojo Maju Jaya Abadi memberikan pengaruh terhadap creative performance mereka. Selain itu, rumusan penelitian selanjutnya adalah kualitas work environment berpengaruh pada creative selfefficacy karyawan pada PT. Putra Mojo Maju Jaya Abadi.

\section{Tujuan Penelitian}

Tujuan penelitian ini yakni untuk menguji dan menganalisis pengaruh kualitas work environment dan creative self-efficacy terhadap creative performance serta menguji dan 
menganalisis pengaruh work environment berpengaruh pada creative self-efficacy pada PT. Putra Mojo Maju Jaya Abadi

\section{TELAAH PUSTAKA}

\section{Work Environment}

Work environment (WP) berfungsi sebagai kumpulan kolektif dari knowledge sharing, motivasi, keadilan prosedural, dan promosi yang mendorong karyawan untuk menghasilkan lebih banyak ide kreatif. Saya berpendapat bahwa dukungan organisasi dan individual sendiri untuk memiliki budaya kooperatif dan persepsi orang dalam memunculkan creative self-efficacy dapat mempengaruhi knowledge sharing, motivasi, keadilan prosedural, dan promosi di work environment (Tsai et al, 2015).

Menurut Dul dan Ceylan (2010), work environment dapat dibedakan menjadi dua dimensi yaitu work environment sosial - organisasional dan work environment fisikal. Work environment sosial - organisasional lebih fokus terhadap konteks sosial dan organisasi karyawan dalam hal desain struktur pekerjaan, kerjasama dalam tim, sistem penghargaan dan gaya kepemimpinan, sedangkan work environment fisikal lebih mengarah kepada konteks lingkungan fisik terhadap karyawan, seperti tempat kerja langsung dan bangunan di sekitarnya. Work environment sosial - organisasional dapat lebih berdampak kepada kesadaran karyawan untuk menampakkan creative self-efficacy dalam dirinya dan hasil dari kesadaran tersebut akan sejajar dengan creative performance dari karyawan itu sendiri. Namun, belum ada data faktual terkait dampak dari work environment fisikal yang bisa berdampak langsung kepada creative self-efficacy karena work environment fisikal hanya berupa bantuan fasilitas dan tunjangan agar karyawan tersebut bisa mengemukakan ide dalam dirinya sendiri. Indikator WP menurut Tsai et al (2015), yaitu knowledge sharing, motivation, procedural justice, dan promotion.

\section{Creative Self-Effiacy}

Creative self-efficacy (CSE) memiliki dasar konsep dari self-efficacy. Menurut Bandura (1995), self-efficacy dideskripsikan sebagai kepercayaan seorang individu akan kapabilitasnya untuk menghasilkan tingkat performa yang telah ditentukan atas suatu peristiwa yang mempengaruhi kehidupan mereka. Self-efficacy berbeda dari selfconfidence karena bersifat umum dan tidak harus dikaitkan dengan tugas atau usaha 
dalam berupaya. Bandura mengklaim bahwa self-efficacy adalah kondisi yang kuat untuk kinerja kreatif, karena self-efficacy meningkatkan motivasi yang mengutamakan bobot dan penekanan pada pemikiran dan tindakan sendiri. Dasar dari self-efficacy sendiri kemudian dikembangkan menjadi creative self-efficacy yang merupakan penjabaran dari konten dan karakteristik yang melekat pada tipe self-efficacy yang lebih spesifik dari konteks self-efficacy yang lebih luas. Dampak dari itu maka creative self-efficacy bersifat spesifik untuk beberapa bagian dan didasarkan pada penilaian seseorang terhadap sumber daya dan kendala dalam bagian tersebut. Menurut Tierney dan Farmer (2002), creative self-efficacy adalah didefinisikan sebagai keyakinan kognitif yang dimiliki seseorang menghasilkan hasil kreatif yang berbanding lurus dengan tingkat self-efficacy yang dimiliki. Hal ini dapat menunjukkan bahwa creative self-efficacy yang tinggi bisa berbanding lurus dengan creative performance jika faktor work environment sendiri juga memberikan dampak positif. Menurut Karwowski (2011), creative self-efficacy tidaklah sama dengan self-rated creativity. Creative self-efficacy lebih diarahkan dan berhubungan langsung terhadap keyakinan individu bahwa diri individu tersebut bisa mampu menjadi pribadi kreatif, bukan berarti seseorang itu kreatif. Meskipun demikian, self-rated creativity secara teoritis merupakan konstruksi yang dekat dari creative self-efficacy. Indikator CSE menurut Badke-Schaub, Brockhus, Kolk, dan Koeman (2014), yaitu asumsi / kepercayaan terhadap diri sendiri mengenai tingkat kreativitas dirinya. Dan penilaian yang berdasarkan bukti keyakinan kreativitas dirinya.

\section{Creative Performance}

Creative performance $(\mathrm{CP})$ dapat didefinisikan sebagai hasil dari penyelesaian tugas dan masalah dengan menggunakan faktor dependen seperti tingkat kreativitas, lingkungan pendukung yang kreatif, dan tingkat creative self-efficacy yang tinggi dari diri individu. Korelasi bermula dari kreativitas diri seseorang dengan menumbuhkan creative selfefficacy dalam dirinya agar bisa selaras dengan work environment yang sesuai. Kolaborasi antara work environment sosial - organisasional dan work environment fisikal akan membantu proses individu dalam menyelesaikan tugas dan permasalahannya, sehingga hasil / solusi dari tugas dan permasalahannya adalah creative performance yang diharapkan. Oleh karena itu, karena creative self-efficacy yang tinggi seharusnya menghasilkan tingkat aspirasi kreatif yang kuat, maka diharapkan akan ada beberapa 
upaya kreatif yang bersifat berkelanjutan, dan menghasilkan creative performance, mengingat penilaian creative self-efficacy yang cukup spesifik (Tierney \& Farmer, 2002). Indikator CP menurut Waples dan Friedrich (2011), yaitu fluency, flexibility, dan originality.

\section{Pengembangan Hipotesis}

Work environment terbagi menjadi dua dimensi yaitu physical work environment dan social work environment. Social work environment harus memiliki nilai kreativitas yang cukup agar faktor sosial berupa kerja sama tim antar karyawan bisa berkembang karena adanya kreativitas dan dengan bantuan work environment fisikal berupa fasilitas yang memadai akan menghasilkan output yang memiliki nilai lebih. Dalam era bisnis modern, kreativitas dan inovasi adalah kunci terpenting dari performa organisasi serta work environment yang kreatif akan memberikan perasaan puas terhadap para karyawan dan memiliki kemungkinan yang kecil karyawan untuk mengundurkan diri (Dul \& Ceylan, 2010). Evaluasi terhadap penelitian ini menunjukkan bahwa work environment dapat meningkatkan kreativitas karyawan dan tersedia alat dan solusi praktis untuk mewujudkan kreativitas yang mendukung work environment. Dengan berfokus pada work environment untuk kreativitas karyawan, kedisiplinan ergonomi dapat membantu organisasi untuk lebih baik menggunakan sumber daya internalnya (karyawan) untuk inovasi produk dan proses (Dul \& Ceylan, 2010). Berdasarkan hasil dari konsep penelitian di atas maka hipotesis yang disusun dalam penelitian ini terkait pengaruh dari WE terhadap CP:

\section{$H_{1}$ : Work environment berpengaruh positif terhadap creative performance}

Hasil studi menurut menunjukkan bahwa creative self-efficacy jika didukung dengan adanya otonomi pekerjaan dan faktor yang berhubungan langsung dengan pekerjaan tersebut. Hal tersebut akan memberikan kebebasan bagi karyawan untuk bertindak sekreatif mungkin sehingga menghasilkan sebuah persepsi yang didasari oleh kreativitas dalam dirinya (Tierney \& Farmer, 2011). Dampak dari creative self-efficacy dalam penelitian ini terkait langsung dengan creative performance. Perbedaan antara kedua gagasan tersebut adalah bahwa self-efficacy kreativitas adalah tentang pikiran seseorang, tentang kemampuan seseorang untuk menjadi kreatif berdasarkan pengetahuan dan keterampilan yang diperoleh. Di sisi lain, creative performance juga berhubungan dengan kegiatan karyawan dalam proses interaktif dengan pelanggan 
perusahaan serta menggunakan cara-cara yang berguna dan teknik yang baru untuk melaksanakan kegiatan ini. Temuan dalam penelitian ini mengungkapkan hubungan yang kuat dan positif antara creative self-efficacy dengan creative performance (Slåtten, 2014). Berdasarkan hasil penelitian di atas maka hipotesis yang disusun dalam penelitian ini terkait pengaruh dari CSE terhadap CP:

$\mathrm{H}_{2}$ : Creative self-efficacy berpengaruh positif terhadap creative performance

Hasil studi yang telah dipaparkan oleh Chong dan Ma (2010) menyatakan bahwa penelitian sebelumnya menunjukkan manajer dapat mencapai tingkat creative performance dan creative self-efficacy yang tinggi dengan menciptakan lingkungan dimana karyawan bebas untuk mencoba hal-hal baru, diizinkan untuk belajar dari kesalahan dan didorong untuk menjadi kreatif. Hal ini dapat mengarah pada siklus yang baik dimana karyawan memenuhi harapan dan ekspektasi dari hasil kreativitas setiap individu, menjadi lebih percaya diri dalam kemampuan kreatif mereka dan terus melakukan aktivitas kreatif yang dapat memperkuat gaya manajemen atasan mereka dan meningkatkan harapan terhadap hasil output organisasi (Chong \& Ma, 2010).

Evaluasi studi dari Dul, Ceylan, dan Jaspers menyatakan bahwa bentuk work environment sosial-organisasi tampaknya memiliki dampak yang lebih kuat pada pembentukan creative self-efficacy dalam invididu daripada work environment fisikal dan juga terdapat pemahaman menganggap work environment sosial-organisasi dan work environment fisik sebagai hal yang penting untuk creative performance karyawan, tetapi lebih diutamakan work environment sosial-organisasi karena sebagai mediasi utama dalam pembentukan creative self-efficacy agar dapat mencapai creative performance yang diharapkan (Tierney \& Farmer, 2002). Berdasarkan hasil penelitian di atas maka hipotesis yang disusun dalam penelitian ini terkait pengaruh dari WE terhadap CSE:

$\mathrm{H}_{3}$ : Work environment berpengaruh positif terhadap creative self-efficacy

\section{METODE PENELITIAN}

Penelitian ini merupakan penelitian kuantitatif yang digunakan untuk meneliti hubungan antar variabel. Penelitian ini dilakukan untuk mengetahui pengaruh yang ditimbulkan oleh work environment dan creative performance melalui creative self-efficacy. Objek dari penelitian ini adalah perusahaan mebel dengan populasi seluruh karyawan divisi desain dan produksi dari PT. Putra Mojo Maju Jaya Abadi sebanyak 67 karyawan dimana 
35 dari divisi produksi dan 32 dari divisi desain. Teknik pengambilan sampel yang digunakan dalam penelitian ini adalah non-probability sampling dengan jenis teknik pengambilan sampel yaitu purposive sampling yakni sudah bekerja lebih dari satu tahun. Dengan teknik pengambilan sampel dari Sugiyono (2017) dengan tingkat kesalahan 5\% maka jumlah sampel yang harus dipenuhi adalah 64 sampel. Penelitian ini sendiri menggunakan sampel sebanyak 67 karyawan.

Metode pengumpulan data dalam penelitian ini mempergunakan kuisioner (angket). Kuisioner ini dibagi menjadi 2 bagian, yaitu identitas responden dan item-item indikator penelitian. Pada bagian identitas responden, responden diminta untuk mengisi usia, jenis kelamin, dan lama bekerja. Item-item ini merupakan pertanyaan yang diturunkan dari indikator variabel dan dipergunakan untuk mengukur variabel penelitian. Terdapat 18 pertanyaan untuk mengukur work environment, 15 pertanyaan untuk mengukur creative self-efficacy, dan 3 pertanyaan untuk mengukur creative performance. Untuk mengukur pertanyaan-pertanyaan tersebut dipergunakan 5 skala Likert, yaitu 1 (sangat tidak setuju) sampai 5 (sangat setuju). Analisis data dilakukan mempergunakan metode Partial Least Square (PLS) dengan mempergunakan software SmartPLS 3.0.

\section{HASIL}

\section{Profil Responden}

Total kuisioner yang dibagikan adalah 67 kuisioner dan semua telah terisi dengan lengkap. Dari 67 responden yang telah mengisi kuisioner, ditemukan bahwa mayoritas responden penelitian merupakan berjenis kelamin laki-laki $(73,13 \%)$. Data juga menunjukan bahwa mayoritas responden memiliki rentang usia antara 36-40 tahun $(23,88 \%)$. Data menunjukkan bahwa mayoritas responden telah lama bekerja hingga 1113 tahun $(31,34 \%)$. Hal ini menunjukkan bahwa responden memiliki loyalitas yang tinggi dan merupakan usia produktif pada perusahaan ini sehingga dapat diketahui bahwa responden sudah merasa nyaman bekerja pada perusahaan ini.

\section{Pengujian Hipotesis}

Pengujian hipotesis diawali dengan melakukan evaluasi model pengukuran (outer model) yang terdiri dari uji validitas (konvergen dan diskriminasi), dan uji reliabilitas. Hasil uji 
validitas dan reliabilitas pada metode PLS menunjukkan bahwa konstruk yang dipergunakan sudah memenuhi kriteria uji validitas dan reliabilitas (Jogiyanto \& Abdilah, 2015). Hasil uji ini dapat dilihat dari nilai outer loading dan cross loading, AVE, dan composite realibility yang berturut-turut berkisar antara 0,703-0,933; 0,583-0,858; 0,948$0,957$.

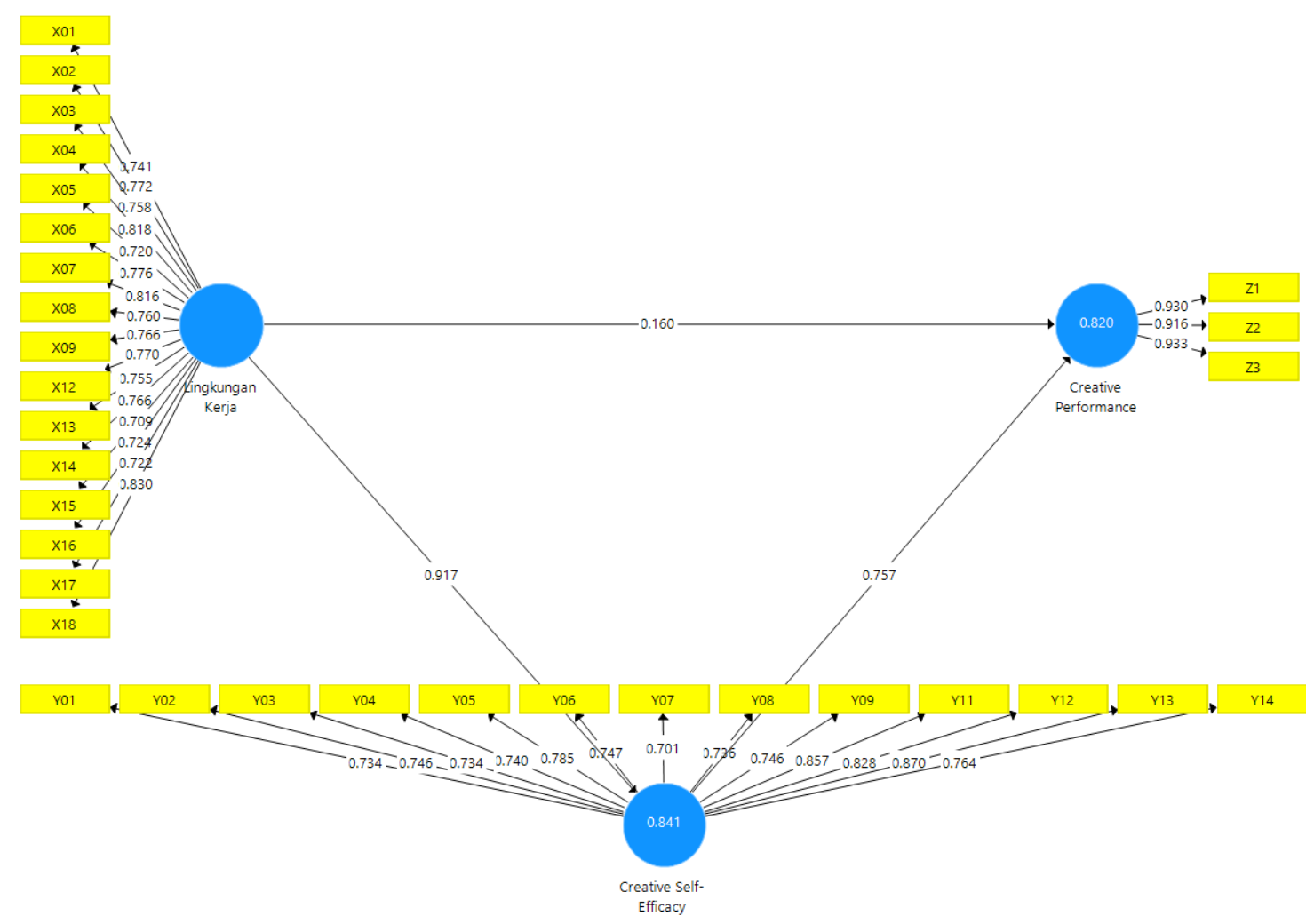

Hasil pengujian hipotesis penelitian dipaparkan pada tabel 1. Pengujian hipotesis untuk menguji hubungan antar variabel penelitian dilakukan dengan melihat nilai $T$ statistic dan p-value yang didapatkan. Dari hasil pengujian hipotesis dengan mempergunakan $T$-statistic ditemukan bahwa WE tidak berpengaruh terhadap CP, CSE berpengaruh terhadap CP, WE berpengaruh terhadap CSE. Ditemukan bahwa 2 dari 3 hipotesis dari hasil pengujian dengan mempergunakan T-statistic dapat diterima dikarenakan nilai $T$ statisticnya tidak memenuhi kriteria yaitu kurang dari 1,96, yaitu WE tidak berpengaruh terhadap CP. Sementara itu, 2 hipotesis diterima karena hasilnya lebih dari kriteria 1,96, yaitu CSE berpengaruh positif terhadap CP, dan WE berpengaruh positif terhadap CSE. 
Tabel 1. Hasil Uji Hipotesis

\begin{tabular}{lllll}
\hline & Original Sample & $\begin{array}{l}\text { Sample } \\
\text { Mean }\end{array}$ & $\begin{array}{l}\text { T- } \\
\text { statistics }\end{array}$ & p-values \\
\hline$W E \rightarrow C P$ & 0,854 & 0,847 & 1,077 & 0,282 \\
$C S E->C P$ & 0,757 & 0,750 & 5.557 & 0,000 \\
$W E \rightarrow C S E$ & 0,917 & 0,914 & 28,832 & 0,000 \\
\hline
\end{tabular}

Berdasarkan Tabel 2, dapat dijelaskan bahwa besarnya keragaman dari data penelitian yang dapat dijelaskan oleh model penelitian adalah sebesar $90.42 \%$, sedangkan 9,58\% sisanya dijelaskan faktor lain di luar model, Oleh karena itu, model penelitian ini dapat dikatakan baik atau sudah relevan karna memiliki goodness of fit yang baik.

$$
\begin{aligned}
& \mathrm{Q}^{2}=1-\left(1-\mathrm{R}_{1}^{2}\right)\left(1-\mathrm{R}_{2}^{2}\right)\left(1-\mathrm{R}_{3}^{2}\right) \ldots\left(1-\mathrm{R}_{\mathrm{p}}^{2}\right) \\
& \mathrm{Q}^{2}=1-\left(1-(0,820)^{2}\right)\left(1-(0,841)^{2}\right) \\
& \mathrm{Q}=0,9042
\end{aligned}
$$

Tabel 2. Nilai $R$-Square

\begin{tabular}{ll}
\hline & $R$ Square \\
\hline Creative performance & 0,820 \\
Creative self-efficacy & 0,841 \\
\hline
\end{tabular}

\section{PEMBAHASAN}

Dari hasil uji hipotesis penelitian ditemukan bahwa WE tidak berpengaruh terhadap CP. Hasil uji hipotesis ini ditolak dan tidak sesuai dengan bunyi hipotesis pertama $\left(H_{l}\right)$ yaitu "WE berpengaruh positif terhadap CP". Di sini, kualitas WE yang tinggi atau rendah tidak akan memberikan pengaruh terhadap CP karyawan pada PT. Putra Mojo Maju Jaya Abadi. Didapati nilai $T$-statistic adalah sebesar 1,077, nilai ini lebih rendah dari nilai kriteria yaitu 1,96 .

Hasil penenlitian ini tidak sama dengan penelitian terdahulu yang dilakukan oleh Tsai et al (2015). Dari hasil tersebut ditemukan bahwa WE mempengaruhi CP pada pada perusahaan pariwisata dan perhotelan sebanyak 320 responden di Taiwan. Hal ini bisa dijelaskan karena karyawan divisi produksi bekerja secara monoton setiap hari sesuai dengan penempatan pada setiap mesin, sehingga setiap karyawan produksi dapat benarbenar memahami cara kerja mesin tersebut bahkan jika mesin tersebut mengalami kerusakan mereka dapat mendiagnosis mesin tersebut dan melaporkan kerusakan kepada kepala divisi untuk diteruskan pada direktur. Karyawan yang bekerja dalam divisi produksi tidak berorientasi terhadap hasil yang kualitas bahan yang lebih bagus atau 
cenderung konsisten selama mesin produksi tetap berfungsi dengan baik dan tidak mengalami kegagalan / malfungsi serta karena pekerjaan mereka hanya pada bagian produksi, apabila diberikan tugas untuk memberikan desain produk mereka tidak yakin akan hasil desainnya sendiri meskipun 60\% karyawan divisi produksi merupakan mantan kerajinan kayu di Lumajang. Karyawan divisi desain berbeda dengan divisi produksi karena mereka harus berkomunikasi untuk saling bertukar pendapat mengenai hasil pekerjaannya. Produk yang dihasilkan oleh divisi desain adalah produk kustom dari perusahaan lain, sehingga hal itu mewajibkan seluruh karyawan divisi untuk tetap menjaga kualitas produk yang dihasilkan. Berkomunikasi merupakan cara yang digunakan agar bisa mendapat masukan dari kepala divisi dan agar bisa membantu sesama divisi jika mengalami kesusahan seperti proses pengukiran yang rumit.

Pengujian hipotesis CSE berpengaruh terhadap CP memperoleh hasil sebesar 5,557. Jika dibandingkan dengan kriteria pengujian hipotesis sebesar 1,96, maka hipotesis ini dapat diterima dikarenakan nilai T-statistic yang diperoleh lebih besar daripada nilai kriteria. Hasil dari pengujian ini adalah hipotesis "CSE berpengaruh positif terhadap CP" dapat diterima. Pengaruh yang ditimbulkan oleh CSE terhadap CP dapat terlihat pada fenomena, salah satu bentuk pengaruh dari CSE terhadap CP adalah karyawan desain saling bertukar ide agar bisa menemukan produk yang cocok untuk memenuhi kebutuhan masyarakat dan memproduksi hasil dari ide tersebut.

Hasil dari penelitian sebelumnya menunjukkan bahwa CSE berpengaruh positif terhadap CP dengan jumlah sampel 145 karyawan (Tierney \& Farmer, 2011). Hasil penelitian tersebut menemukan bahwa salah satu bukti pengaruh CSE terhadap CP dapat dilihat dan diukur melalui asumsi / kepercayaan terhadap diri sendiri mengenai tingkat kreativitas dirinya dan penilaian yang berdasarkan bukti keyakinan kreativitas dirinya. Kedua penilaian tersebut mampu menunjukkan seberapa besar dampak tingkat CSE terhadap CP.

Memiliki tingkat CSE yang tinggi juga berdampak dalam proses kerja yang lebih cepat dan tanggap dalam menghadapi sebuah masalah terutama pada karyawan divisi desain dimana mereka dituntut agar bisa menghasilkan ide produk baru untuk menyesuaikan dengan kebutuhan pasar. Memiliki keyakinan yang tinggi atas kreativitas dirinya membuat mereka terdorong untuk menciptakan desain baru untuk PT. Putra Mojo Maju Jaya Abadi. Di luar produk pesanan perusahaan lain, karyawan desain saling 
bertukar ide agar bisa menemukan produk yang cocok untuk memenuhi kebutuhan masyarakat dengan menggunakan bahan serbuk kayu terutama dalam rangka menerapkan lingkungan yang zero-waste. Fakta di lapangan yang disampaikan oleh Kepala Divisi Desain pada umumnya dalam memberikan ide baru dalam desain produk setidaknya satu karyawan dapat memberikan 5 hingga 6 ide yang berbeda. Banyaknya ide tersebut sangat membantu dalam memberikan referensi untuk pemilihan desain yang sesuai kebutuhan.

Dari hasil pengujian hipotesis ditemukan bahwa WE berpengaruh positif terhadap CSE. Nilai T-statistic yang diperoleh lebih tinggi dari kriteria 1,96 yaitu 28,832. Hal ini membuktikan hipotesis penelitian ini yang berbunyi demikian "WE berpengaruh positif terhadap CSE" diterima. Dari hasil penelitian yang dilakukan oleh Dul, Ceylan, dan Jaspers (2011) ditemukan bahwa WE berpengaruh terhadap CSE dengan sampel yang diteliti sebanyak 409 karyawan yang bekerja di Belanda.

Hasil dari pengujian hipotesis ini sejalan dengan fakta di lapangan bahwa WE yang memiliki kualitas bagus jika melalui mediasi CSE maka akan memberikan hasil kinerja yang bagus seperti CP yang bagus. dukungan antar karyawan dan kepala divisi berupa masukan dan arahan ditambah dengan asumsi dan pengalaman yang berorientasi terhadap kreativitas maka menghasilkan kreativitas yang bagus. Fakta di lapangan terbukti saat karyawan desain berunding untuk menghasilkan desain produk baru atau prototipe. Hasil tersebut memang diserahkan atas nama kepala divisi, namun dalam proses pengerjaan dilakukan bersama-sama baik kepala divisi ataupun karyawan. Pengerjaan produk tersebut menunjukkan bahwa mereka memiliki asumsi terhadap dirinya yang tinggi memberikan hasil produk yang bagus dan sesuai harapan. Klaim dari kepala divisi dan direktur menyatakan bahwa hasil produknya mendapat komentar positif dari beberapa perusahaan yang bekerja sama dengan PT. Putra Mojo Maju Jaya Abadi sehingga meminta kustom produk serupa dengan sedikit perubahan.

\section{KESIMPULAN DAN SARAN}

Tujuan dari penelitian ini adalah untuk mengetahui pengaruh yang ditimbulkan oleh WE terhadap CP yang melalui mediasi CSE terhadap perusahaan mebel. Hasil dari penelitian mayoritas sama dengan hasil yang dari penelitian sebelumnya yang dilakukan pada industri yang berbeda dari penelitian ini. Dari hasil penelitian ini ditemukan bahwa kualitas lingkungan kerja akan mempengaruhi tingginya efikasi diri kreatif yang selanjutnya akan mempengaruhi kreativitas seseorang dalam bekerja. Namun kualitas 
lingkungan kerja tidak mempengaruhi langsung creative performance seseorang. Dalam hal ini diharapkan agar perusahaan dapat meningkatkan tingkat creative self-efficacy karyawan dan kualitas work environment agar hasil dari creative performance bisa meningkatkan jumlah kapasitas produksi baik dari desain ataupun produksi material.

Ke depan, perusahaan perlu memperhatikan kualitas lingkungan kerja misalnya melalui pelaksanaan placement test diharapkan agar bisa lebih interaktif lagi terutama pada kepala divisi yang secara langsung memantau kinerja sementara dari calon karyawan. Perusahaan juga bisa mendorong peningkatan creative self-efficacy dari karyawan dengan menghimbau kepala divisi desain agar bisa tetap memberi dorongan kepada karyawan desain agar berani mengemukakan ide ketika bekerja.

Untuk penelitian selanjutnya, topik serupa bisa diperdalam dengan menambah jumlah perusahaan yang diteliti sehingga menambah jumlah sampel yang digunakan. Penelitian juga dapat diperluas dengan meneliti sektor industri yang berbeda.

\section{DAFTAR PUSTAKA}

ASMINDO. (2020). Peningkatan kapasitas UKM mebel \& kerajinan bali dalam implementasi \& pemenuhan persyaratan untuk mendapatkan sertifikat SVLK program kerjasama ASMINDO dengan FAO FLEGT. Retrieved from http://asmindo.or.id/2020/01/14/peningkatan-kapasitas-ukm-mebel-kerajinanbali-dalam-implementasi-pemenuhan-persyaratan-untuk-mendapatkan-sertifikatsvlk-program-kerjasama-asmindo-dengan-fao-flegt-program-amaris-hoteldenpasar/

Badan Pusat Statistik. (2018). Banyaknya perusahaan industri besar dan sedang menurut KBLI 2 digit di Jawa Timur tahun 2011-2015. Retrieved from https://jatim.bps.go.id/statictable/2018/02/15/983/banyaknya-perusahaan-industribesar-dan-sedang-menurut-kbli-2-digit-jawa-timur-tahun-2011-2015.html

Badan Pusat Statistik. (2018). Banyaknya tenaga kerja per perusahaan industri besar dan sedang menurut KBLI 2 digit di Jawa Timur Tahun 2011-2015. Retrieved from https://jatim.bps.go.id/statictable/2018/02/15/987/banyaknya-tenaga-kerja-perperusahaan-industri-besar-dan-sedang-menurut-kbli-2-digit-di-jawa-timur-tahun2011-2015.html 
Bandura, Albert. (1995). Self-efficacy in changing societies. Cambridge: Cambridge University Press

Badke-Schaub, P., Brockhus, S., van der Kolk, T., \& Koeman, B. (2014). The influence of creative self-efficacy on creative performane. International Design Conference - Design 2014, 437-444. Retrieved from https://www.designsociety.org/publication/35188/THE+INFLUENCE+OF+CRE ATIVE+SELF-EFFICACY+ON+CREATIVE+PERFORMANCE

Chong, E., \& Ma, X. (2010). The influence of individual factors, supervision and work environment on creative self-efficacy. Creativity And Innovation Management, 19(3), 233-247.

De Clercq, D., Haq, I., \& Azeem, M. (2019). Workplace ostracism and job performance: Roles of self-efficacy and job level. Personnel Review, 48(1), 184-203. doi: 10.1108/pr-02-2017-0039

Dul, J., Ceylan, C., \& Jaspers, F. (2011). Knowledge workers' creativity and the role of the physical work environment. Human Resource Management, 50(6), 715-734. doi: 10.1002/hrm.20454

Dul, J. \& Ceylan, C. (2010). Work environments for employee creativity. Ergonomics, $54(1), 12-20$

Jogiyanto, H. H., \& Abdilah, W. (2015). Partial Least Square (PLS) - Alternatif Structural Equation Modelling (SEM) dalam penelitian bisnis. Yogyakarta: ANDI. Karwowski, M. (2011). It doesn't hurt to ask...But sometimes it hurts to believe: Polish students' creative self-efficacy and its predictors. Psychology of Aesthetics Creativity and the Arts, 5(2), 154-164.

Katadata. (2016). Statistik: Di tingkat global, kreativitas Indonesia termasuk paling rendah. Retrieved from https://databoks.katadata.co.id/datapublish/2016/08/17/ditingkat-global-kreativitas-indonesia-termasuk-paling-rendah

Qerja. (2018). Survey kepuasan dan kepercayaan karyawan dalam bekerja. Retrieved from https://www.qerja.com/journal/view/10701-infografik-kepuasankepercayaan-diri-kinerja-pekerja/

Slåtten, T. (2014). Determinants and effects of employee's creative self-efficacy on innovative activities. International Journal of Quality and Service Sciences. 6(4), $326-347$ 
Sugiyono, S. (2017). Metode penelitian kuantitatif, kualitatif, dan R\&D. Bandung: Alfabeta.

Tierney, P., \& Farmer, S.M. (2002). Creative self-efficacy: Its potential antecedents and relationship to creative performance. Academy of Management Journal, 45(6), 1137-1148.

Tierney, P. \& Farmer, S.M. (2011). Creative self-efficacy development and creative performance over time. Journal of Applied Psychology, 96(2), 277-293.

Tsai, C., Horng, J., Liu, C. \& Hu, D. (2015). Work environment and atmosphere: The role of organizational support in the creativity performance of tourism and hospitality organizations. International Journal of Hospitality Management, 46, 26-35.

Vision Media. (2016). IFEX 2017 Usung Inovasi dan Kreativitas Industri Mebel. Retrieved from https://www.himki-indonesia.com/post/view/60-id-ifex-2017usung-inovasi-dan-kreativitas-industri-mebel

Waples, E., \& Friedrich, T. (2011). Managing creative performance. Advances in developing human resources, 13(3), 366-385. doi: 10.1177/1523422311424713 